\title{
LA ENSEÑANZA DE LA RELIGIÓN: UN TEMA PENDIENTE DE LA LIBERTAD RELIGIOSA EN MÉXICO
}

\author{
Religious education: A Pending Issue \\ of Religious Freedom in Mexico
}

\author{
MANUEL ANTONIO MUREDDU GONZÁLEZ \\ Universidad Autónoma de Querétaro \\ mamureddug@gmail.com
}

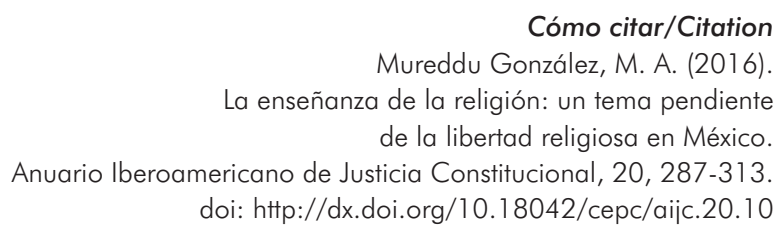

Resumen

El derecho humano a la enseñanza religiosa es un derecho humano contenido en distintos instrumentos internacionales aplicables en México. Sus implicaciones y la forma como ha de interpretarse tiene fundamento tanto en documentos internacionales como en las pautas dadas por la teoría de derechos fundamentales. Sin embargo, su aplicabilidad supone una serie de obligaciones positivas a cargo del Estado que se contrapone directamente con la forma privatista de concebir al hecho religioso en México. Aun así, la transformación constitucional del México actual abre las puertas a una nueva forma de entender un derecho humano tradicionalmente olvidado en este país.

1 Licenciado en Derecho por la Universidad Autónoma de Querétaro. Becario Fulbright-García Robles. 


\section{Palabras clave}

Laicidad; derechos humanos; enseñanza religiosa; educación pública; México.

\section{Abstract}

The human right to religious teaching is a human right contained in distinct international instruments applicable in Mexico. Its implications and the way it may be interpreted have its origin both in international documents and in the rules given by the fundamental rights theory. However, its applicability supposes a series of positive obligations assumed by the State that may oppose directly with the private way the religious fact is conceived in Mexico. Nevertheless, the constitutional transformation in today's Mexico opens the doors to a new way of understanding a human right that has been traditionally forgotten in this country.

\section{Keywords}

Secularism; human rights; religious teaching; public education; Mexico. 


\section{SUMARIO}

I. INTRODUCCIÓN. II. DESMENUZANDO LA LIBERTAD Y EL DERECHO A LA ENSEÑANZA RELIGIOSA: 1. La prestación normativa; 2. La prestación fáctica: 2.1. La enseñanza acerca de la religión; 2.2. La enseñanza de la religión; 2.3. Instrucción religiosa y educación pública, żla prevalencia de lo privado ante lo público? III. CONCLUSIONES. IV. BIBLIOGRAFÍA.

\section{INTRODUCCIÓN}

Dentro de todas las posiciones de derecho fundamental que podemos encontrar en las disposiciones de la libertad religiosa, el derecho de los padres y tutores a que sus hijos o pupilos sean educados conforme a sus convicciones es quizá el derecho que por su impacto social y político resulta más complicado y controvertido. Pensado como atentatorio de la laicidad del Estado - como sucede en México- este derecho atrae numerosas complicaciones prácticas, que requieren de una precisión interpretativa suficiente para su aplicación, de modo que entre su disposición y su ejercicio no nos encontremos frente a un choque entre la laicidad del Estado y la libertad religiosa, sino ante el más legítimo y genuino ejercicio de esta libertad fundamental.

En México, las reformas constitucionales de junio de 2011 introdujeron al sistema normativo la aplicabilidad directa de aquellas normas de derechos humanos contenidas en tratados internacionales que, antes de esa fecha, no habían recibido la aplicación debida.

La reforma al art. 1 de la Constitución mexicana representó una auténtica metamorfosis al colocar a los derechos humanos como la nueva piedra angular sobre la que se sostiene el sistema, pero quizá más aun, al abrir su fuente a instrumentos que van más allá de la propia Constitución e instituir entre estos una relación cualitativa y no jerárquica. En los términos empleados por la propia Suprema Corte de Justicia de la Nación, los derechos humanos se tornan en el parámetro de regularidad constitucional a partir del cual controlar y calificar la dinámica jurídica nacional. 
Este parámetro se entiende alrededor de tres elementos esenciales que quedaron insertos en los primeros tres párrafos del citado art. 1, y que son: a) la alusión explícita a los derechos humanos contenidos en tratados internacionales, y como resultado de ello, la posibilidad de oponer y exigir directamente los derechos humanos contenidos en estos; b) el establecimiento del principio pro persona como paradigma interpretativo de las normas de derechos humanos, y c) el alcance garantista de las obligaciones generadas por estos derechos y los principios rectores de las mismas (universalidad, interdependencia, indivisibilidad y progresividad).

Cada uno de estos elementos bastaría por sí solo para que corrieran ríos de tinta en su análisis. A efectos del presente trabajo destaca la particularidad que tiene la integración de los derechos humanos, con independencia de su fuente, como parte de ese único parámetro constitucional que ya no plantea distinción en su origen sino en su espectro de protección. Preguntémonos entonces, ¿̇los derechos humanos establecidos en tratados internacionales de los que el Estado mexicano forma parte, serán oponibles y exigibles procesalmente de la misma manera que lo sería un derecho directamente establecido en la Constitución?

La respuesta es sí. El texto reformado del primer párrafo del art. 1 constitucional genera una clasificación en la que se reconoce a los derechos humanos como un único estándar de protección interno, con independencia de su fuente. Así, el también llamado «bloque de constitucionalidad» conforma un único patrón cualitativo en el que la base es la propia cualidad de ser un derecho humano, y no la fuente normativa de la que este se derive, lo que se traduce en una verdadera apropiación de los derechos humanos contenidos en tratados internacionales al derecho interno, $y$ de las interpretaciones que a estos han extendido los órganos autorizados a nivel internacional.

La conjunción de este bloque de constitucionalidad con el también reciente principio pro persona ocasiona que el nuevo paradigma interpretativo del sistema jurídico mexicano resida en la selección de la norma que más favorezca a la persona, con independencia de su fuente.

Así, de alguna manera podríamos hablar de un control de constitucionalidad que desde el punto de vista sustantivo incorpora también un control de convencionalidad, pues a fin de cuentas ambos forman un único parámetro de regularidad constitucional basada en consideraciones cualitativas y no jerárquicas o de fuente. Esto ocasiona que lo dispuesto en este nuevo bloque no solo resulte ser un todo que aglutine un conjunto normativo a partir del cual se evaluará el resto del sistema jurídico, sino que además resulte enteramente exigible en términos sustantivos y procesales, abriendo la puerta al ejercicio de derechos anteriormente inusitados en México.

A su vez, estos derechos deben entenderse a la luz del tercer párrafo del mismo art. 1 constitucional, que establece, entre otras cosas, la obligación del Estado de garantizar el ejercicio de los mismos, lo que para efectos del presen- 
te le plantea irremediablemente una obligación positiva que en el derecho a la enseñanza religiosa puede tener particulares manifestaciones.

Con ello, la libertad religiosa es uno de esos derechos humanos cuya aplicabilidad directa se ve ampliamente beneficiada por su consideración como parte de un único estándar de protección interno. Por la propia precariedad con que la libertad religiosa había sido legislada en nuestro derecho nacional, y su contraria amplitud con que ha sido contemplada en el derecho internacional, la nueva comprensión integral de este derecho introduce una serie de temáticas y figuras que si de por sí ya eran temas pendientes en nuestro país, ahora son además jurídicamente exigibles. Inevitablemente, uno de estos temas es el derecho a la enseñanza religiosa.

En el presente artículo habremos de abordar la temática relativa a este derecho humano partiendo del contenido de las disposiciones normativas que lo contienen, vistas a la luz de la abstracción propia de los derechos fundamentales. Posteriormente, revisaremos la interpretación y la forma como este derecho ha de entenderse a la luz de ciertos documentos para, finalmente, formular una prospectiva de este derecho en México.

\section{DESMENUZANDO LA LIBERTAD Y EL DERECHO A LA ENSEÑANZA RELIGIOSA}

Dentro de este bloque de normatividad aplicable en México, y contemplada de forma concreta por dos ordenamientos jurídicos internacionales, la Convención Americana sobre Derechos Humanos en su art. 12.4, y el Pacto Internacional de Derechos Civiles y Políticos en el 18.4, la libertad de enseñanza religiosa se encuentra como parte de un derecho humano. En ambos casos, dicha libertad se formula en términos coincidentes cuya observancia resulta necesaria para determinar a ciencia cierta cuál es el carácter de este derecho en su abstracción como un derecho fundamental.

Ambas disposiciones establecen:

\begin{tabular}{|l|l|}
\hline \multicolumn{1}{|c|}{$\begin{array}{c}\text { Convención Americana } \\
\text { sobre Derechos Humanos }\end{array}$} & \multicolumn{1}{c|}{$\begin{array}{c}\text { Pacto Internacional } \\
\text { de Derechos Civiles y Políticos }\end{array}$} \\
\hline $\begin{array}{l}\text { Los padres, y en su caso los tutores tienen } \\
\text { derecho a que sus hijos o pupilos reciban } \\
\text { la educación religiosa y moral que esté de } \\
\text { acuerdo con sus propias convicciones. }\end{array}$ & $\begin{array}{l}\text { Los Estados parte en el presente Pacto se } \\
\text { comprometen a respetar la libertad de los } \\
\text { padres y, en su caso, de los tutores legales, } \\
\text { para garantizar que los hijos reciban la } \\
\text { educación religiosa y moral que esté de } \\
\text { acuerdo con sus propias convicciones. }\end{array}$ \\
\hline
\end{tabular}


Lo que equivale a los siguientes elementos comunes:

a) establecen un derecho humano contenido como parte de la libertad religiosa;

b) lo atribuyen expresamente a los padres de familia y tutores;

c) se trata de un derecho a algo: a que los hijos o pupilos sean educados conforme a las convicciones religiosas de sus padres o tutores.

La libertad religiosa es a la luz de la teoría de derechos fundamentales de Robert Alexy lo que se denomina como «un derecho como un todo" por la variedad de posiciones jurídicas de derecho humano que acarrea. Una de dichas posiciones destacables es la que se percibe en la concepción y ejercicio del derecho a la enseñanza religiosa de los hijos respecto de las creencias de los padres en la educación que estos reciban.

Dada su posición dentro de un sistema jurídico, es una libertad que posee diversas implicaciones conductuales para el Estado y necesarias para su satisfacción. Su estructura, en cuanto a la posición de derecho fundamental de un derecho a algo, implica una prestación específica del Estado y además lo convierte en sujeto obligado a la prestación de la educación como derecho fundamental, recibiendo una obligación específica en este derecho.

La escuela, como menciona el informe A/HRC/16/53 de diciembre de 2010 emitido por Heiner Bielefeldt, relator especial sobre la libertad de religión o de creencias del Consejo de Derechos Humanos de la Organización de las Naciones Unidas (2010: 19) «es la institución formal más importante para el ejercicio del derecho a la educación y constituye un lugar de aprendizaje, desarrollo social y encuentro social.». En ella refiere, no solo se brindan al alumno los conocimientos y la información necesarias para el desarrollo y aprendizaje de distintas disciplinas, sino que también son lugares de auténtica expresión social donde se encuentran y se genera la convivencia de personas de distintos orígenes y entornos étnicos, sociales, económicos, culturales e, invariablemente, religiosos. El derecho a la enseñanza religiosa, en cuanto producto de la libertad religiosa y su conjunción con el derecho a la educación, no debe entenderse de manera aislada, sino en todo caso atendiendo a uno de sus elementos indispensables, el derecho a la educación.

Respecto del derecho a la educación, difícilmente puede negarse que una disposición que enuncie algo así como "los padres tienen derecho a que sus hijos reciban educación", o "toda persona tiene derecho a recibir educación", no implica que se trata del derecho a recibir algo, es decir, que se trata de un derecho a una prestación. Como tal genera una obligación a cargo de un sujeto obligado a impartir educación, el Estado, para cuya consecución han de realizarse toda una serie de conductas cuyo objeto último será garantizar 
que toda persona pueda recibirla, lo que implica irremediablemente, toda clase de medidas que, sin mencionarlas exhaustivamente, comprenden desde la creación de los marcos normativos más generales en los que se atribuyen competencias y facultades, como su pormenorización a través de la creación de planes de estudio, la contratación de personal y proveedores, la formulación de partidas presupuestarias que lo permitan, la creación de los espacios físicos en que habrá de prestarse la educación y, finalmente, la prestación efectiva, material y de calidad de la educación a través de su impartición en escuelas a cargo del Estado. De esa manera, no parece haber duda de que el derecho a la educación es un derecho prestacional en los dos sentidos que contempla la propia teoría iusfundamentalista, fáctico y normativo.

Igualmente, entendido como un derecho social, Carbonell (2004: 761) estima que en el derecho a la educación confluyen tres condiciones fundamentales esenciales para justificar su existencia como derecho prestacional:

1. El individuo es incapaz de satisfacer por sí solo, o con la ayuda de su entorno social más inmediato, sus necesidades básicas.

2. Surgen riesgos sociales que no pueden ser enfrentados por las vías tradicionales, basadas en la responsabilidad individual.

3. Se desarrolla la convicción social de que el Estado debe asumir la necesidad de garantizar a todos los ciudadanos un mínimo de bienestar; si el Estado no cumpliera con esa obligación, se pondría en duda su legitimidad.

Por mi parte, más que un derecho social creo que resulta más acertado hablar de un derecho prestacional que, atendiendo a José Ramón Cossío, contiene una significación axiológica que lo identifica con un derecho de igualdad en la medida en que su establecimiento es expresión de una búsqueda de equiparación o generación de condiciones de equidad entre los diversos actores sociales. Así, materialmente nos encontraríamos frente a un derecho prestacional con una implicación axiológica de igualdad, lo que a la postre nos permitirá identificar con mayor facilidad cuál es el objeto del derecho fundamental en cuestión, en lugar de colocarlo dentro de una categoría ciertamente compleja como resulta la de un derecho social, cargada de un fuerte significado político, y habitualmente relacionada más bien con movimientos sociales. (Cossío Díaz, 1989: 46).

La relevancia de este punto se alcanza en el reconocimiento como un derecho prestacional, pues ello resulta suficiente para que podamos partir de la comprensión del derecho a la educación religiosa en el mismo sentido, y que no se determina autónomamente, sino que resulta interdependiente tanto de la libertad religiosa como del derecho a la educación. Dicho de otra manera, el derecho a que los menores sean educados conforme a las convicciones 
religiosas de los padres, no es más que el efecto de un derecho derivado de la libertad religiosa en su conjunción sistemática con el derecho a la educación, pues como tal, lo que hace es introducir una característica definitoria a la educación prestada por el Estado en satisfacción de tal derecho.

Entonces, la delicadeza del derecho de enseñanza religiosa se coloca en el punto en que, en tanto la educación es una prestación que el Estado se encuentra obligado a otorgar, su comprensión dentro de un sistema jurídico trae como consecuencia que el mismo Estado deba asegurar de alguna manera que la educación de los menores sea conforme a las convicciones religiosas de sus padres, o de lo contrario estaría limitando un importante aspecto de la libertad religiosa, de los derechos de los padres a su organización familiar, e incluso de los derechos de los niños.

Pero entonces, si consideramos al derecho a la enseñanza religiosa como un elemento que se adhiere como una característica adjunta al derecho a la educación, ¿es también un derecho prestacional que el Estado debe satisfacer? En cuanto es un derecho a algo, y sobre todo vinculado con la educación que el Estado debe garantizar, sí podemos considerar que es un derecho prestacional. El Estado, estando obligado a la prestación de la educación, también se encuentra obligado a garantizar que la educación que imparta sea consecuente con la libertad y la diversidad religiosa de sus beneficiarios. La respuesta de dicha pregunta se alimenta de dos elementos importantes de los derechos prestacionales. Por un lado, hay que atender al sentido tradicional con el que estos han sido comprendidos, pues con su expresión «se vincula la concepción de un derecho a algo que el titular del derecho, en caso de que dispusiera de medios financieros suficientes y encontrase en el mercado una oferta suficiente, podría obtener también de personas privadas [...]» (Alexy, 2007: 391), ante lo cual es necesario atender a conciencia cuál es la circunstancia real de este derecho en muchos países y, particularmente, en el nuestro. Recuérdense las palabras de José Luis Soberanes (2000: 51), quien con mucha sensatez refiriera que el derecho de los padres a que sus hijos sean educados conforme a sus convicciones religiosas, es en México un derecho reservado a la clase económica y socialmente beneficiada, es decir, únicamente al alcance de aquellos que cuentan con las condiciones necesarias para enviar a sus hijos a una escuela privada en la que puedan recibir una educación conforme a un ideario atento a sus creencias religiosas, suponiendo en todo caso la necesaria presencia de una institución con estas características en su población, lo que habitualmente no sucede en núcleos de población rural o económicamente desfavorecidos.

Un segundo elemento que considerar atiende preferentemente al carácter axiológico al que se ha referido José Ramón Cossío al hablar de los derechos prestacionales. Se trata de derechos que imponen al Estado la persecución de ciertos fines, o sea, que llevan implícita una exigencia que redunde en benefi- 
cio de sus titulares (Alexy, 2007: 393). En este caso, son dos los fines que no debemos perder de vista al hablar de este tema: por un lado, una reiteración de la constante búsqueda de igualdad en sociedades con profundas diferencias económicas que generan un fuerte rezago en el desarrollo social de los más desfavorecidos, quienes de forma prácticamente inevitable se ven privados de facto de la posibilidad de acceder a medios educativos no brindados por el Estado; y, en un segundo lugar, en una perpetua lucha por la libertad religiosa, que ciertamente se vería mermada si no se brindasen medios para garantizar las condiciones de su ejercicio, medios como lo son las prestaciones que de cualquier modo haga el Estado. No debemos olvidar que el sentido último de la laicidad es garantizar a la libertad religiosa como principio orientador de las actuaciones del Estado y los poderes públicos, y cuyo límite prestacional y normativo reside en no ejercer una labor que exceda las medidas necesarias para garantizar las condiciones necesarias para el ejercicio de la libertad religiosa sin dar preferencia a confesión religiosa alguna.

Esta libertad de enseñanza religiosa en la educación pública, como un derecho prestacional implica su conceptualización en los dos sentidos que teóricamente ha enunciado Robert Alexy para los derechos a acciones positivas: como prestaciones normativas y como prestaciones fácticas.

\section{LA PRESTACIÓN NORMATIVA}

En su implicación normativa, el Estado debe asumir su obligación de crear disposiciones normativas y administrativas que garanticen tanto la protección como el ejercicio efectivo de los derechos (Alexy, 2007: 172).

La prestación normativa debe ser acorde con las condiciones que le son establecidas en el contenido del derecho mismo, a efecto de hacerlo realizable o efectivo. Aunado a ello, debe suscribirse de distintas modalidades, características y cualidades que en todo caso no deben ser entendidas de forma aislada, sino atendiendo a otras figuras fundamentales del Estado, como lo debe ser su carácter laico e implícitamente neutral.

Por otra parte, atendiendo a los sistemas de atribuciones y de reparto de competencias y facultades que resultan comunes a todos los sistemas jurídicos, y que son indispensables para la tutela del principio fundamental de seguridad jurídica, para que el Estado pueda optar a la prestación material del derecho a la enseñanza religiosa, primeramente debe agotar la prestación normativa en virtud de la cual se establezcan las condiciones sobre las que habrá de desarrollarse la actividad de los poderes públicos. Es decir, deberá establecerse con claridad en qué y cómo pueden intervenir las autoridades.

En su prestación de garantías normativas que le permitan garantizar el derecho fundamental tutelado, el Estado implementa medidas organizativas 
suficientes para obtener el resultado acorde a la satisfacción del derecho fundamental (Alexy, 2007: 419). Este derecho prestacional, en cuanto requiere de una medida procedimental que organice el correcto funcionamiento del derecho fundamental, tiene por objeto la creación de normas y medidas dirigidas a cumplir con el fin que propone. Este tipo de actividades redunda, sobre todo, en obligaciones generadas a cargo de los órganos legislativos (no limitativamente, puesto que la obligación es a cargo del todo el Estado y no solo del creador de leyes), quienes adquieren el deber de dictar las normas de observancia general necesarias en la materia.

El deber de adoptar disposiciones de derecho interno consagrado en el art. 2 de la Convención Americana sobre Derechos Humanos, no hace más que recalcar el deber prestacional normativo que suscribe el Estado como obligación para garantizar los derechos fundamentales que habrá de tutelar, y que dice:

ART. 2.- - Deber de Adoptar Disposiciones de Derecho Interno

Si el ejercicio de los derechos y libertades mencionados en el Art. 1 no estuviere ya garantizado por disposiciones legislativas o de otro carácter, los Estados Partes se comprometen a adoptar, con arreglo a sus procedimientos constitucionales y a las disposiciones de esta convención, las medidas legislativas o de otro carácter que fueren necesarias para hacer efectivos tales derechos y libertades.

En el caso de la libertad de enseñanza religiosa en México, es obvio que se encuentra incumplido, ante la ausencia de legislación regulatoria en la materia.

Desafortunadamente, el estatus de este tipo de derechos prestacionales, referido habitualmente por Robert Alexy como derechos a la organización y al procedimiento, encuentra un fuerte obstáculo en su exigibilidad jurisdiccional por carecer de un carácter subjetivo en sentido estricto, sobre todo cuando la implicación que acarrearía es eminentemente legislativa. Concretamente, en nuestro sistema jurídico el reclamo que ante los tribunales podría llevarse por el incumplimiento del Estado a su deber de adaptar disposiciones de derecho interno a la luz de cualquier disposición supranacional, conocido en la práctica forense como "omisión legislativa», no ha resultado próspero atendiendo a uno de los principios rectores del juicio de amparo, el principio de relativi$\mathrm{dad}^{2}$, el cual en el caso mexicano brinda al Estado la posibilidad de evadir su responsabilidad.

2 Omisión legislativa. Es improcedente el juicio de amparo en su contra, conforme al art. 73, fracción xvinI, de la ley de la materia, en relación con el art. 107, fracción II, párrafo primero, de la Constitución Política de los Estados Unidos Mexicanos. Época: 
En cualquier caso, la prestación normativa supone la creación de normas adscritas de derecho fundamental en virtud de las cuales pueda generarse una relación de precisión con las que se determine de qué manera el Estado habrá de dar cumplimiento a su obligación a satisfacer los derechos de las personas. En la medida que el Estado genere dichas medidas de seguridad normativa, habrá prestado satisfactoriamente dicha prestación.

\section{LA PRESTACIÓN FÁCTICA}

En su implicación fáctica, el Estado materialmente debe asumir obligaciones de dar o de hacer; ya hemos dicho que este, en cuanto sujeto obligado en el derecho a la educación, es el mismo obligado a garantizar que la educación se imparta conforme a las convicciones religiosas de sus beneficiaros, enunciando con ello un rasgo característico de cómo debe ser la educación que se imparta estatalmente. La implicación fáctica de esta prestación reside entonces en que se imparta educación que cumpla con estas características, y que además, pueda llevarse a cabo dentro de un centro público. Sin embargo, la prestación fáctica que tienen los padres y tutores a que sus hijos y pupilos sean educados conforme a sus convicciones religiosas, supone más complicaciones que los que podemos encontrar ante la prestación normativa, quizá por la naturaleza técnica que tiene el anterior y que se agota mediante el establecimiento de disposiciones.

De cualquier manera, para la determinación de los alcances de esta prestación, vale la pena que revisemos lo referido por el punto 6 de la Observación General 22 del Comité de Derechos Humanos de la ONU al referir a este derecho contenido en el art. 18.4 del Pacto Internacional de Derechos Civiles y Políticos:

6. El Comité opina que el párrafo 4 del art. 18 permite que en la escuela pública se imparta enseñanza de materias tales como la historia general de las religiones y la ética siempre que ello se haga de manera neutral y objetiva. La libertad de los padres o de los tutores legales de garantizar que los hijos reciban una educación religiosa y moral que esté de acuerdo con sus propias convicciones proclamada en el párrafo 4 del art. 18 está relacionada con la garantía de la libertad de enseñar una religión o creencias que se recoge en el párrafo 1 del mismo art. 18. El Comité señala que la educación obligatoria que incluya el adoctrinamiento en una religión o unas creencias particulares es incompatible con el párrafo 4 del art. 18, a menos que se

décima época; registro: 2002843; instancia: Segunda Sala; tipo de tesis: aislada; fuente: Semanario Judicial de la Federación y su Gaceta; libro xviI, febrero de 2013, tomo 2; materia(s): común; tesis: 2a. VIII/2013 (10a.): pág. 1164. 
hayan previsto exenciones y posibilidades que estén de acuerdo con los deseos de los padres o tutores.

Precisamente lo que busca afirmarse a través de la Observación General 22 es que el Estado, en una actuación congruente al principio de laicidad, y atendiendo principalmente al respeto de la libertad religiosa, principio orientador de la actuación de los poderes públicos y definición de la laicidad, no puede permitir actuaciones estatales que impongan valores religiosos determinados a quienes no los comparten en virtud de su propia libertad religiosa, pues de lo contrario, volvería a convertirse en un brazo secular de la religión (Porras Ramírez, 2013: 74).

La enseñanza religiosa en la educación pública solo tiene cabida si se da en congruencia con el principio de laicidad del Estado en un mandato inexcusable de imparcialidad estatal. En realidad, en México la laicidad se ve como un complemento de la ausencia de fanatismos y los prejuicios.

Como un paréntesis, vale la pena mencionar que este es un elemento que planteará un importante reto para la aplicación directa de los tratados internacionales en la libertad de enseñanza religiosa en México. Y es que si bien desde su origen, la existencia del bloque de constitucionalidad supuso un único estándar de protección interno sin distingos a priori respecto de la fuente del derecho humano, la afinación de esta norma a través de la labor interpretativa de la Suprema Corte de Justicia ha resultado en la conformación de un controvertido criterio que podría suponer la neutralización práctica de dicho bloque.

La jurisprudencia derivada de la Contradicción de Tesis 293/2011³, en la que la Corte resolvió que frente aquellos derechos humanos contenidos en tratados internacionales respecto de los cuales pudiera haber una restricción expresa en la Constitución, prevalecería lo dispuesto en esta última, vino a generar una regla universal en la que, de acuerdo al ministro José Ramón Cossío Díaz (2015: 47), disidente del criterio mayoritario, interpretativamente el derecho convencional siempre terminará por ceder frente al derecho constitucional, desplazando la naturaleza y aplicación del principio pro persona, y corrompiendo la propia naturaleza del bloque de constitucionalidad.

3 Derechos humanos contenidos en la Constitución y en los tratados internacionales. Constituyen el parámetro de control de regularidad constitucional, pero cuando en la constitución haya una restricción expresa al ejercicio de aquellos, se debe estar a lo que establece el texto constitucional. Época: décima época; registro: 2006224; instancia: pleno; tipo de tesis: jurisprudencia; fuente: Gaceta del Semanario Judicial de la Federación; libro 5, abril de 2014, tomo i; materia(s): constitucional; tesis: p./j. 20/2014 (10a.); pág. 202. 
Esta jurisprudencia puede resultar de particular importancia en la práctica de este derecho si consideramos el dilema interpretativo real al que potencialmente se enfrentarán las autoridades del Estado, al calificar la posible enseñanza religiosa en la educación pública frente al principio de laicidad del Estado, consagrado de manera particular en el art. 3, fracción I de la Constitución, y el art. 40, por cuanto ven a la educación.

La posible respuesta a dicho planteamiento será un auténtico desafío para el principio pro persona y para la propia progresividad de los derechos humanos. ¿Qué entenderemos por Estado laico, aquel Estado que restringe cualquier posibilidad religiosa en el espacio público, o aquel que garantiza plenamente los términos de una interpretación preexistente para el ejercicio de la libertad religiosa? Según como se llegue a contestar esa pregunta, el derecho a la enseñanza religiosa en México tendrá cabida en la esfera pública.

Ahora, volviendo a la interpretación que los órganos autorizados han dado para la prestación de este derecho, son dos los modelos bajo los que al tenor de esta interpretación del Comité de Derechos Humanos de la ONU, válidamente puede existir enseñanza religiosa en la educación pública. Dichos modelos son coincidentes con los referidos por Heiner Bielefeldt, relator especial sobre la libertad de religión o de creencias del Consejo de Derechos Humanos de la Organización de las Naciones Unidas en el informe A/ HRC/16/53 de 15 diciembre de 2010. Ambos modelos o enfoques pedagógicos son: a) la enseñanza acerca de la religión, y b) la enseñanza de la religión. La diferenciación conceptual entre ambos modelos es esencial, pues si bien pudieran confundirse y pensar que se trata de figuras coincidentes, el enfoque y el carácter con que ambos modelos se desarrollan es muy relevante y sus implicaciones y consecuencias son radicalmente distintas.

Por lo anterior, a continuación exponemos brevemente cada uno de estos modelos, pero no sin antes comentar que los elementos que ahora analizaremos atienden directamente a una interpretación de la normatividad del Pacto Internacional de Derechos Civiles y Políticos y no así directamente a la Convención Americana sobre Derechos Humanos, cuyo texto normativo relacionado con esta cuestión nunca ha sido objeto de interpretación oficial por la Corte Interamericana de Derechos Humanos, por lo que nuestra exposición se limitará particularmente a aquellos criterios ya suscritos de forma oficial.

\subsection{La enseñanza acerca de la religión}

El Pacto Internacional de Derechos Civiles y Políticos considera como una opción factible que en términos de su art. 18.4 puedan impartirse en la escuela pública materias en las que se enseñe historia general de las religiones. 
A esta posibilidad es a lo que se le ha conocido como «enseñanza acerca de las religiones».

En este tipo de enseñanza lo que se busca es brindar al alumno un marco general y objetivo alrededor del fenómeno religioso y de sus distintas manifestaciones.

La enseñanza acerca de las religiones presenta una posibilidad en la que se lleva a cabo un análisis riguroso y objetivo, sin tomar partida por una actitud religiosa específica o por una confesión en particular. En atención a este modelo, la Oficina de Instituciones Democráticas y Derechos Humanos (ODIHR) de la Organization for Security and Cooperation in Europe (OSCE), en un intento por sentar criterios y bases objetivas que puedan servir como sustento para la prestación efectiva de un derecho de esta categoría, creó en 2008 un documento al que se le conoce como los Principios orientadores de Toledo sobre la enseñanza acerca de la religión y creencias en las escuelas públicas, en cuyos objetivos acerca de la necesidad de establecer dichos principios alrededor de la enseñanza acerca de la religión, establecieron la base sobre la que habrá de entenderse verdaderamente en qué consiste:

El punto de partida consiste en comprender que la enseñanza acerca de religiones y creencias no tiene una orientación confesional ni va dirigida a impulsar la práctica religiosa. Aspira a que el alumno tome conciencia de las religiones y creencias, pero no le presiona para que acepte ninguna de ellas; apoya el estudio sobre religiones y creencias, no su práctica; pone a los alumnos en contacto con una diversidad de puntos de vista religiosos y no religiosos, pero no impone ninguna visión particular; plantea una educación sobre religiones y creencias sin promover ni denigrar a ninguna de ellas; informa a los alumnos sobre diversas religiones y creencias, pero no intenta que los alumnos se adecúen o se conviertan a ninguna religión o creencia particular. El estudio sobre las religiones y creencias ha de basarse en un sólido conocimiento académico, lo cual es una condición previa esencial para proporcionar a los alumnos una comprensión a la vez equitativa y más profunda de las diversas tradiciones en materia de creencias (Office for Democratic Institutions and Human Rights, 2008: 23-24).

Este tipo de enseñanza, de conformidad a los mismos principios formulados por la ODIHR, se caracteriza por lo siguiente:

El «aprendizaje acerca de la religión» incluye una indagación sobre la naturaleza de las religiones, sus creencias, enseñanzas y formas de vida, fuentes, prácticas y formas de expresión. Abarca el conocimiento y la comprensión, por parte del alumno, de las diversas religiones, y la forma en que se relacionan entre sí, así como el estudio de la naturaleza y las características de la religión. Incluye las habilidades de interpretación, análisis y explicación. Los alumnos aprenden a comunicar sus conocimien- 
tos y su comprensión empleando un lenguaje especializado (Office for Democratic Institutions and Human Rights, 2008: 50).

Es decir, se trata de una enseñanza en la que se pretende abordar a la religiosidad y las creencias religiosas específicas como objetos de estudio independientes y a la luz de un análisis objetivo no dogmático o tendencioso; no se produce en atención de la fe, sino de un conocimiento con pretensiones científicas y objetivas, en el que prima la difusión de información sobre las religiones. $\mathrm{O}$ tal como lo explica Heiner Bielefeldt en el informe A/HRC/16/53: «En este sentido, la divulgación de información no forma parte de la enseñanza teológica, sino que se acerca más bien a otras disciplinas, como la historia o las ciencias sociales» (Consejo de Derechos Humanos, 2010: 11).

Con su impartición no se busca una atención a la creencia religiosa de los beneficiarios, sino más bien una enseñanza sobre las distintas religiones que, de forma objetiva e imparcial, logre generar un ambiente de tolerancia y empatía respecto de las diversas creencias religiosas que puedan existir (Office for Democratic Institutions and Human Rights, 2008: 51), particularmente aquellas que estén presentes dentro de la sociedad en la que se imparte con independencia de si se trata de religiones mayoritarias o no.

Uno de los grandes retos en las sociedades modernas - y particularmente de las pluriculturales - es la eliminación de los estereotipos negativos y prejuicios existentes en relación con ciertas comunidades, algunas de ellas por motivos religiosos. En la erradicación de dichos males es inevitable una promoción activa de los derechos humanos y su ejercicio, y la educación es una herramienta indispensable para alcanzar dichos fines. La enseñanza escolar desempeña, por ello, una labor insustituible tanto para alcanzar un ejercicio efectivo de la libertad religiosa como para generar redes de comprensión y comunicación personal entre miembros de distintas comunidades, muchas veces socialmente contrapuestas.

Por otro lado, la inclusión de un modelo de estas características también resulta útil para el conocimiento de la propia sociedad y de la propia cultura en que se desarrollan las personas. Hoy resulta inevitable reconocer que la religión ha sido, a lo largo de la historia, parte decisiva en la proyección de la historia, el arte y la cultura, la filosofía e incluso la geografía del mundo moderno, motivo por el que resulta al menos necesario un reconocimiento de la importancia objetiva que ha tenido el hecho religioso a lo largo del tiempo. En tal medida, una enseñanza objetiva acerca del hecho religioso y sus diversas manifestaciones se antoja conveniente para el desarrollo integral de las facultades y conocimiento de las nuevas generaciones, hecho que no pasara inadvertido Régis Debray, célebre socialista francés que tras prácticamente 120 años de estricto laicismo en la educación pública francesa, propusiera 
públicamente la inclusión de una asignatura de enseñanza del hecho religioso en las escuelas de Francia.

En pocas palabras, podríamos decir que la esencia de este modelo radica en que se trata de una enseñanza sustentada en conocimientos objetivos racionales y no en una transmisión de la fe. Sin embargo, con independencia de todas sus bondades, este modelo por sí solo no satisface el derecho de los padres y tutores a que sus hijos sean educados conforme a sus convicciones religiosas, pues en lugar de transmitir una convicción estudia aquellas que ya existen. No obstante, conociendo la noble intención - y sobre todo la relevancia- de este modelo en la búsqueda de la eliminación de los estereotipos negativos y los prejuicios sociales alrededor de distintos grupos religiosos, creo que debería considerarse la posibilidad de que este subsistiera a la par del modelo que a continuación presentaremos, pues si bien en uno se ejercita propiamente el derecho a la enseñanza religiosa y a la difusión de la propia religión, en el otro se sientan las bases objetivas y formalmente académicas sobre las que se consolidará la tolerancia y la neutralidad necesarias para garantizar objetivamente la libertad religiosa.

La enseñanza acerca de la religión representa la posibilidad de prevenir la discriminación por causa de religión y es una forma de evitar fanatismos, ya que su prohibición a través de un laicismo beligerante y extremo, puede acabar por privilegiar y dar vida a una posición tan intolerante como la imposición forzosa de una religión.

\subsection{La enseñanza de la religión}

Este segundo modelo, si bien más controversial, satisface más directamente el derecho a la enseñanza religiosa.

De acuerdo al Informe A/HRC/16/53, el objeto de este modelo es la instrucción del alumno en una religión o creencia concreta en atención a los dogmas y principios propios de esta, y acorde al deseo de sus padres o, en ciertos casos, del alumno; dicho en otras palabras, su instrucción religiosa (Consejo de Derechos Humanos, 2010: 16). En consideración de Víctor J. Vázquez Alonso (2012: 574):

[...] lo que realmente diferencia a esta materia con respecto a cualquier otra que sea objeto de enseñanza es que su finalidad, más allá de la transmisión de conocimientos, es la transmisión de unos determinados valores, en definitiva, que con ella se pretende que el alumno no solo adquiera conocimientos religiosos sino también que reciba una formación moral vinculada a la fe que abrazan sus padres. 
Su práctica debe producirse como un reflejo de los intereses y exigencias de los segmentos poblacionales presentes en el sistema educativo en que se imparta, motivo por el que la citada Observación General 22 contempla en este modelo su posibilidad en el ejercicio del derecho humano referido, siempre y cuando se contemple dentro de un plano de posibilidades y exenciones para los padres de familia o el alumno suscriptor. $\mathrm{O}$ sea, que de ninguna manera debe existir el adoctrinamiento obligatorio respecto de una confesión religiosa específica en una escuela pública, sea cual sea la religión. E incluso si se diere el caso que resultare obligatorio el ingreso a una asignatura de esta categoría, necesariamente deben contemplarse cursos alternativos no religiosos para aquellos alumnos que no profesen ninguna fe o cuya fe no forme parte de la instrucción brindada escolarmente. De lo contrario, se trataría de una medida atentatoria de esta libertad.

Atendiendo entonces al carácter de obligatoriedad con que se imparte dentro del curílculo escolar, la instrucción religiosa puede formularse de dos maneras:

a) como una asignatura de suscripción libre o voluntaria, extracurricular. En este modo extracurricular, e incluso fuera del horario escolar ordinario, existe la posibilidad de obtener instrucción religiosa de acuerdo al deseo de los padres o del propio alumno, eso sí, impartida como una prestación extracurricular organizada por el Estado del mismo modo que podría suceder con clases culturales o deportivas.

b) Como una asignatura de suscripción obligatoria, curricular. Para que este caso resulte operativo dentro de un régimen de libertad religiosa, necesariamente debe partir del supuesto de que existan distintas posibilidades religiosas y no religiosas dentro de las asignaturas que en este rubro se impartan, de manera que: 1) nadie se vea forzado a asistir a la instrucción de una religión a la que no es afín, o que siendo afín, simplemente opte por no suscribir la asignatura, y 2) que quienes no deseen suscribir una instrucción religiosa, puedan optar por la inscripción a asignaturas ajenas a todo contenido religioso, o incluso a horas de estudio libre ${ }^{4}$.

4 Como sucede en España con la posibilidad que se presenta con la impartición de la asignatura «Educación para la ciudadanía», o en Alemania, donde opcionalmente puede optarse por clases de Filosofía, Ética, Valores y Normas o tiempo de estudio libre en lugar de la instrucción religiosa que se brinda respecto de las religiones católica, evangélica, ortodoxa, neoapostólica y judía. 
Si bien la instrucción religiosa es una forma de garantizar el derecho de los padres a la enseñanza religiosa de sus hijos conforme a sus convicciones religiosas, la misma instrucción en la escuela pública siempre deberá ir acompañada de las garantías específicas para el respeto de los miembros de religiones minoritarias, así como de aquellos que no profesan religión alguna. Por ello, el ingreso o no del alumno en una asignatura de instrucción religiosa deberá regirse por el principio de voluntariedad de la asistencia religiosa (Ollero, 2009: 163), y nunca deberá acarrear consigo una sanción de hecho o derecho que de alguna manera genere una diferencia, una desventaja o un perjuicio en detrimento de quien no acuda a la instrucción religiosa.

De igual manera, no debe existir ninguna clase de dificultad o diferenciación en el trato escolar para el alumno que opte por no recibir instrucción religiosa, pues a fin de cuentas no deben pasarse por alto los términos del art. 18.2 del Pacto Internacional de Derechos Civiles y Políticos, que establece que «nadie será objeto de medidas coercitivas que puedan menoscabar su libertad de tener o de adoptar la religión o las creencias de su elección». Toda medida que tenga por objeto forzar o influir sobre la libertad del alumno al recibir instrucción religiosa, será por completo contraria a la propia naturaleza regulatoria de la libertad religiosa de acuerdo a la normativa internacional.

En dicho ámbito, el reconocimiento de este principio de voluntariedad de la enseñanza religiosa llega a tal grado que incluso la Corte Constitucional Italiana, en análisis de la situación propia de dicho país, ha aclarado que aquellos alumnos que escojan no recibir enseñanza religiosa, no están ni siquiera obligados a permanecer en las instalaciones escolares al tiempo en que se imparte la enseñanza religiosa (Presidenza del Consiglio dei Ministri, 2013: 44), principio que ha sido sostenido esencialmente en los mismos términos por la Ley Orgánica de Educación en España, que contempla que los alumnos que no quieran enseñanza religiosa podrán hacer lo que quieran durante el horario dedicado a esta, e incluso que en aquellos casos en que la clase se imparta al principio o al final de la jornada, podrán entrar después o salir antes de clases (Celador Angón, 2009: 92).

Ante ello, si lo que se pretende es promover y respetar el derecho de la libertad religiosa, es inevitable considerar que ello de ninguna manera podrá suceder en un ámbito en que se obliga o condiciona a los alumnos a recibir instrucción religiosa. Y es que si bien es cierto que dicha instrucción es una forma de garantizar uno de los diversos derechos derivados de la libertad de religión, es igualmente cierto que la imposición de una actitud religiosa a través de la enseñanza de una cierta confesión no haría más que agravar las violaciones a este derecho fundamental.

En cualquier caso, no debe pasarse por alto que en la satisfacción de este derecho, el Estado de ninguna manera puede obviar su obligación iusfun- 
damental considerando que da cumplimiento parcialmente a su obligación permitiendo la instrucción religiosa en las escuelas privadas (Consejo de Derechos Humanos, 2010: 18); y es que si bien la educación privada es una vía mediante la cual puede efectuarse la educación de los alumnos conforme a un ideario integral derivado de un pensamiento religioso válidamente suscrito como fundamento educativo en el ámbito privado de acuerdo a los deseos de los padres, lo cierto es que la posibilidad de acceso a una educación de este tipo responde primordialmente a la verificación de condiciones económicas. Además, no hay que olvidar que el hecho de que nos encontremos frente a una nota definitoria de la educación que el Estado ha de prestar como sujeto obligado en el derecho a la educación, es suficiente para considerar que este de ninguna manera puede relevarse de su obligación arrojándola como una prerrogativa únicamente en el ámbito privado, o de lo contrario, el Estado sería omiso en su deber de garantizar las medidas suficientes para un pleno goce de la libertad religiosa. Dicha interpretación que relega a un ámbito enteramente privado (ya sea en la educación privada o incluso en la exclusividad del seno familiar) a la enseñanza religiosa, no es más que un efecto de una postura laicista tendiente a considerar a las manifestaciones propias de la libertad religiosa como hechos privados que deben ser desterrados de los espacios públicos, actitud típica de una concepción privatista del hecho religioso (Ollero, 2009: 216)

Precisamente, una de las características que le viene dada por ser un derecho humano es que no debe estar de ninguna manera supeditado a condiciones que excedan de forma alguna la única condición de ser humano, es decir, que de ninguna manera puede dejarse el ejercicio de un derecho de esta categoría a la verificación de condiciones alternas, o en este caso, económicas.

Ahora, no obstante la relativamente sencilla exposición del modelo de enseñanza de la religión que hemos propuesto, un modelo de estas características acarrea una serie de cuestiones que deben ser resueltas en aras de un funcionamiento equilibrado y conforme a sus objetivos. A continuación analizamos brevemente algunas de estas cuestiones:

\subsection{Instrucción religiosa y educación pública, żla prevalencia de lo privado ante lo público?}

Una de las cuestiones de más relevancia cuando hablamos de la enseñanza de la religión, se encuentra en el potencial enfrentamiento producido entre las posiciones morales públicas y privadas. Al Estado no le pertenecen los espacios públicos y en tal medida, al apropiarse de estos mediante la imposición de discursos oficiales, está faltando a su deber de neutralidad no únicamente religiosa sino también política e ideológica. 
Las religiones no solamente se conforman por una serie de creencias dogmáticas, ritos o tradiciones; también se integran por todo un entramado de valores y consideraciones morales que moldean y determinan a los individuos en su cosmovisión y su relación con el mundo. La enseñanza de la religión supone también la transmisión de dichos valores como reflejo de una moral privada que se imparte a la par de la moral oficial que el Estado imparte predeterminadamente.

Sin embargo, ¿debe el Estado tolerar la irrupción de las religiones en el ámbito educativo? Puede parecer un conflicto derivado de diferencias eminentemente terminológicas, pero la respuesta es que no: el Estado no debe tolerar las religiones, debe respetarlas.

La referencia a algo como objeto de tolerancia no parte de una visión de neutralidad, sino de una visión tendenciosa en virtud de la cual preexiste un componente de rechazo en contra de aquello que se tolera. Es decir, solo tiene sentido decir que tolero algo en la medida en que no estoy de acuerdo con ello, pues si lo estuviera, no tendría necesidad de tolerarlo.

Sobre la tolerancia Andrés Ollero se pronuncia en términos bastante similares, aunque la introducción que dicho autor realiza alrededor de la concepción de la primera a la luz de la verdad, es elemental para entender cómo y por qué al Estado le corresponde una actitud de respeto más que de tolerancia frente a la religión. Dichos tres elementos tal cual han sido entendidos por Ollero (2010: 238), son:

- Primero: solo cabe tolerar lo que, de suyo, es rechazable; hace falta por tanto un elemento objetivo que nos diga si algo es rechazable o no.

- En segundo lugar, se tolera en aras de un valor ético superior. Si no contáramos con un valor ético objetivamente superior, no habría motivo para tolerar nada.

- En tercer lugar, nunca cabe franquear la frontera de lo intolerable; alguien tendrá, pues, que marcar, desde una verdad, qué es intolerable y qué no lo es.

La tolerancia necesita entonces una brújula en virtud de la cual al menos se tenga un concepto propio acerca de aquello que se considera como debido e indebido. Por ello mismo necesitamos dos elementos esenciales para entender la tolerancia: por un lado, un valor ético superior que es empleado como una referencia para la actitud deóntica que recaiga sobre todo lo demás; y en segundo lugar, una concepción de la verdad en virtud de la cual pueda definirse a la luz de sí misma, qué debe y qué no debe ser tolerado.

Pero entonces, ¿qué cosas resultan tolerables? Resumo la respuesta en lo siguiente: es tolerable todo aquello que, no adecuándose a nuestra concepción de la verdad o al valor ético superior que sostenemos, tampoco cae en el campo de la prohibición. 
Así, por ejemplo, habrá para quien la afinidad a una determinada corriente filosófica resulte una cuestión de tolerancia pero, en cambio, no podrá existir tolerancia respecto de la comisión de un delito, toda vez que este se encuentra terminantemente y objetivamente prohibido, con independencia del sistema de valores que suscribamos.

Lo intolerable, por su parte, acaba por ser únicamente aquello que resulta terminantemente prohibido. Serán intolerables aquellas conductas que atenten contra la autonomía del individuo, es decir, aquellas que lo opriman de manera que no le permitan emprender decisiones autónomas, así como aquellas decisiones que si bien autónomas, generan un daño en otras personas. (Del Águila, 2010: 367).

En tal medida, si partimos del presupuesto de que cuando hablamos de tolerar algo necesariamente nos estamos refiriendo a algo que, en función de nuestra concepción de la verdad y del valor ético superior con que configuramos nuestra vida, es indebido sin llegar a estar prohibido, entonces es claro que la valoración de algo como tolerable necesariamente se forma a partir de una visión propia — quizá compartida - como cierta.

Por lo tanto, en un sistema laico en el que se pretenda el gobierno de la libertad religiosa como un principio orientador de las actuaciones del Estado, las morales privadas — en este caso las religiones - no deben ser objeto de tolerancia sino de respeto, puesto que considerarlas como objeto de tolerancia supondría valorarlas como fenómenos que, si bien no están prohibidos, tampoco son deseables. Es decir, cuando hablamos de que las religiones deben ser toleradas, no partimos de una concepción objetivamente neutral respecto de ellas, sino de una visión negativa del propio fenómeno religioso. Una neutralidad objetiva respecto de las religiones se construye más bien a través de su valoración en una visión de respeto incondicionado. Así, cuando hablamos de que un Estado tolera las religiones, y particularmente su difusión como parte de una moral privada, estamos hablando de que la postura originaria de este es de desaprobación y no de neutralidad frente al fenómeno religioso (McConnell, 2013: 778). Este engañoso discurso de la tolerancia de las religiones se suscita particularmente cuando se da por supuesta la tentación fundamentalista de las religiones, lo que no es más que un prejuicio cultural que lo único que hace es confirmar un paradójico fundamentalismo laicista que coloca a las religiones como fenómenos culturales indeseables (Ollero, 2010: 17). No olvidemos las palabras de John Rawls cuando decía que el que alguien pueda sostener una doctrina razonable de modo irrazonable, no convierte a la doctrina en algo irrazonable (Ollero, 2010: 19).

Consecuentemente, la implicación negativa de un Estado que tolera las religiones se encuentra en que si se manifiesta de dicha manera, es porque parte de un presupuesto en el que, en contraposición con lo que propugnan 
las religiones, posee una moralidad propia con respecto a la cual las creencias religiosas resultan fuera de lugar, sea por un rechazo a su manifestación fenomenológica o simplemente por un desacuerdo con los postulados que estas sostienen. Es decir, porque en oposición de la moral privada propuesta por las confesiones religiosas, cuenta con una moral oficial casi constituida a modo de religión cívica. Por su parte, los Estados habitualmente construyen su discurso moral alrededor de conceptos netamente procedimentales desvinculados de contenidos o criterios sustanciales que busquen orientar conductas ciertas hacia el valor del bien. El problema se suscita en que en sociedades multiculturales como las nuestras, en las que apelar a un consenso homogéneo y mayoritario se antoja una labor complicada y pretensiosa, la solución política resulta en desvincular las concepciones éticas aceptables de sus contenidos sustanciales, optando por privilegiar más bien una concepción que se pretende universal únicamente por su carácter procedimental. En palabras más sencillas, ante la imposibilidad de un consenso sustancial en las formas de pensar, la solución recae ya no en formar un consenso material o en asumir una postura ideológicamente fija, sino en más bien asumir la consideración de que dichas posturas han de relegarse al ámbito de lo privado, reservándose para lo público aquellas que, o bien sean meramente procedimentales y que por lo mismo no tiendan a un imperialismo ideológico, o bien que sean producto de un único consenso configurado a través de una supuesta voluntad manifiesta en las figuras estatales.

El problema de que el Estado asuma una concepción procedimental del bien, reside en que eventualmente dicha concepción acaba por transformarse en una postura oficialista que, en tanto se configura a través del derecho y de un discurso político dominante, acaba por apropiarse del espacio público y de aquello que se entiende como razonable. Al hacerlo, se transforma en un auténtico discurso oficial ahora también dotado de contenido con convicciones propias que incluso llega a imponer, entrando en franco conflicto con las concepciones privadas del bien. Y ese es precisamente el punto en que el Estado comienza a hablar de tolerar las religiones, pues ya no las ve desde una estricta neutralidad, sino desde la visión que él mismo ha generado, visión en la que estas podrían configurarse como algo indeseable. Atendiendo a esa problemática «en un sistema jurídico político basado en el pluralismo, la libertad ideológica y religiosa de los individuos y la aconfesionalidad del Estado, todas las instituciones públicas y muy especialmente los centros docentes han de ser, en efecto, ideológicamente neutrales» (Ollero, 2009: 209). La verdadera neutralidad respeta, no tolera.

La neutralidad que ha de suscribir el Estado en materia educativa, tiene como implicación esencial que los centros o escuelas públicas no podrán contar con una ciencia, doctrina o cosmovisión oficial, incluso si esta se sustentara 
en criterios así adoptados por el Estado (Contreras Mazario, 2002: 129), o al menos no en la medida en que a través de esta se presente como preferible sobre aquellas derivadas del ámbito privado, pues en tanto una visión de estas características fuera suscrita por la educación pública, faltaría a su deber de neutralidad y respeto al promover la propia doctrina como correcta, oficial y obligatoria.

Claros ejemplos en este sentido podemos encontrar en la evolución que ha sostenido nuestro art. 3 constitucional, que desde 1917 ha ido enmarcándose en un oficialismo que ha ido desde la imposición laicista, su caracterización como socialista en su reforma de 1934 o, incluso, la valoración que llega a hacer de la democracia como «un sistema de vida fundado en el constante mejoramiento económico, social y cultural del pueblo» a través de su reforma de 1946 (Soto Flores, 2013).

La actitud del Estado, en cambio, ha de formarse alrededor de la equidad y el respeto que se debe a todas las personas y a sus concepciones del mundo, a través del fortalecimiento de instituciones comunes a través de las cuales muchas y variadas formas de vida puedan coexistir (Del Águila, 2010: 371). Por ello, al hablar de las constituciones, Gustavo Zagrebelsky (2011: 13) refiere que la tarea de estas no es la de establecer directamente un proyecto predeterminado de vida en común para sus miembros, sino la de realizar las condiciones que posibiliten la vida en común.

La libertad de enseñanza propia de la educación pública debe configurarse entonces como un instrumento de la investigación científica, y la docencia no como un instrumento de difusión de ideología (Contreras Mazario, 2002: 129). Sin embargo, la anterior no es una prohibición que deba aplicar únicamente en contra de las confesiones religiosas, sino también en contra del propio Estado, de manera que no pueda privilegiar una ideología cierta — sea propia o no- únicamente por ser la considerada preferible. Por ello, debe evitarse que a través de la educación pueda someterse a sus beneficiarios a cualquier clase de adoctrinamiento ideológico, sea incluso de fuentes y conocimiento de impartición oficial. Así las cosas, la enseñanza de la religión en las escuelas públicas ha de verse como la satisfacción de parte del Estado al deseo de los padres de que sus hijos reciban esta enseñanza, confirmando con ello derechos humanos de igualdad y libertad, además de la obligación de los padres a enviar a sus hijos a recibir educación, previniendo fanatismos y discriminaciones.

Reiteremos la incompetencia del Estado al tratar del fondo de los contenidos ideológicos que han de resultar aceptables, particularmente los religiosos. Por ello, un Estado que impone una moral oficial en la escuela pública en detrimento de las convicciones propias de quienes acudan a esta educación, violenta incluso su ámbito de competencia y trasgrede su deber de neutrali- 
dad a través de una conducta que él mismo comete. No es casualidad que por dicho deber de neutralidad, establecido constitucionalmente a través de la No establishment clause $e^{5}$ contenida en la primera enmienda de la Constitución de los Estados Unidos, la tradición constitucional y jurisprudencial norteamericana haya sido tan reiterativa en su consideración de que al Estado de ninguna manera compete la calificación de la veracidad o la pertinencia de aquellos discursos cargados de ideología, siempre y cuando no caigan en formas o fondos que de alguna manera puedan violentar la libertad de otras personas, principio elemental y sobre el que se edifica la misma clause:

[...] there is no reason to think that the government will make the right choices about what speech to regulate. Politicians are likely to suppress speech when it advances their own political interests, which is unlikely to coincide with the suppression of speech that causes the most net harm. The same argument can be made about freedom of religion, with even greater force. A cornerstone of the American constitutional tradition of religious freedom is the view - held by all stripes of religious opinion - that the government has no competence to judge religious truth (McConnell, 2013: 795).

Claro, lo anterior debe formularse dentro de su debida aclaración de que, si bien no debe privilegiarse una ideología como cierta o preferible dentro de los centros docentes, la misma neutralidad y respeto con que deben ser tratadas las formas ideológicas en la educación, ha de ser vista en todo momento a la luz de la libertad religiosa por la cual tanto los menores como los padres tendrán derecho a que en la educación pública que se brinde, puedan libremente acceder a una enseñanza religiosa y moral que esté de acuerdo a sus propias convicciones, pero siempre condicionada a un ámbito de libertad. De lo contrario, a través del ejercicio de su derecho violentarían los mismos principios elementales para la construcción de una educación incluyente y respetuosa de los derechos humanos. En ningún momento olvidemos que la observancia de la libertad religiosa ha de operar como un auténtico principio orientador de las actuaciones estatales:

[...] se advierte que tampoco queda comprometida la neutralidad religiosa del Estado porque éste colabore en la financiación de la educación religiosa demandada por los padres o, simplemente, en la financiación de las iglesias. Cuando el Estado colabora de diversas maneras no lo hace porque reconozca que tales

5 "Congress shall make no law respecting an establishment of religion, or prohibiting the free exercise thereof» (el Congreso no podrá hacer leyes referentes al establecimiento de religión o a la prohibición del libre ejercicio de la misma). 
enseñanzas o tales confesiones o prácticas religiosas representen la verdadera fe, sino porque tal ayuda representa una forma más o menos necesaria o conveniente de facilitar el pleno ejercicio de la libertad religiosa de los ciudadanos (hay que volver a insistir en que la libertad religiosa no se reduce a rezar o participar en actos de culto, sino que para ella resulta muy importante su despliegue externo) (Santamaría, 2012: 37).

Por ello, la enseñanza de la religión no ha de entenderse como la prevalencia de lo privado frente a lo público, de las ideologías de unos cuantos sean muchos o pocos - frente a la ideología que es de todos sin ser de nadie; ha de entenderse como la prevalencia de la libertad frente a la opresión, como el derecho a suscribir una verdad sin tener que condicionarla a aquella que nos sea impuesta, como la materialización de uno de los aspectos más íntimos de la libertad religiosa.

\section{CONCLUSIONES}

¿Es verdaderamente posible la enseñanza religiosa en la educación pública en México? Es decir, ¿la sola introducción de este derecho a nuestro orden interno a través de los tratados internacionales en materia de derechos humanos, es suficiente para que sea un derecho directamente exigible al Estado mexicano? Sí. La conformación de un estándar de protección interno, también llamado «bloque de constitucionalidad», conformado por un único conjunto normativo basado en la cualidad de derechos humanos, y no en una relación de fuente o jerarquía, han hecho que el derecho a la enseñanza religiosa como un elemento de la libertad religiosa expresamente contemplado en tratados internacionales por la Convención Americana sobre Derechos Humanos y el Pacto Internacional de Derechos Civiles y Políticos en sus arts. 12.4 y 18.4, respectivamente, sea un ejemplo de aplicación directa en México de un derecho humano contenido en un tratado internacional.

Este derecho, según ha sido interpretado por órganos internacionales como el Comité de Derechos Humanos de la Organización de las Naciones Unidas en su Observación General 22, puede llegar a manifestarse de dos maneras: a) a través de un modelo en el que de manera objetiva se instruya a los alumnos acerca de la historia y las variadas manifestaciones del fenómeno religioso, a lo que se le conoce como enseñanza acerca de la religión, y b) a través de un modelo en el que a través de ciertas restricciones y exenciones se permite la instrucción religiosa de quien así lo desee, también conocido como enseñanza de la religión. 
En ambos casos, se trata de un derecho fundamental que, en tanto constituye una característica definitoria de la educación que preste el Estado, recae en un modelo prestacional fáctico y normativo sin cuyo desarrollo difícilmente podría verse satisfecho.

Sin embargo, son dos las cuestiones que tendrían que dilucidarse para el ejercicio práctico del derecho a la enseñanza religiosa en México:

a) ¿cómo habrá de asumirse la categorización laica del Estado y de la educación en México? ¿Será como la de un Estado que tutela sin distingos la libertad religiosa de sus gobernados, hasta el extremo de permitir la libre enseñanza religiosa en espacios como la escuela pública? o ¿será más bien a través del laicismo propio del Estado que neutraliza cuanto pueda tener un sesgo religioso dentro de la esfera pública? La respuesta a esta pregunta será clave para determinar si a la luz de la Jurisprudencia mexicana existe una restricción constitucional que limite el ejercicio de este derecho fundamental, y por lo tanto, su exigencia directa al Estado a partir de los tratados internacionales, que aunque existe a priori, bien podría verse limitada.

b) En segundo lugar, ¿asumirá el Estado mexicano el alcance prestacional que este derecho a la enseñanza religiosa tiene? o ¿evitará asumir dicha responsabilidad al tratar de relegar este derecho a una posición iusfundamental con implicaciones de una conducta estatal de protección negativa en el ejercicio exclusivo del seno familiar o de la educación privada? Como un derecho social, la educación ha gozado históricamente de mayor efectividad que una simple norma programática. Desde su origen en 1917 se le comprendía como uno de los pocos derechos que implicarían una verdadera acción positiva del Estado, pero ¿ello será suficiente para que a través de la misma prestación educativa ahora se haga manifiesto el derecho a la enseñanza religiosa, como una simple nota definitoria de la educación acorde al ejercicio pleno de la libertad religiosa?

Según los hechos con que se responda a estas dos preguntas, será la forma en la que se podría llegar a materializar el derecho a la enseñanza religiosa como una expresión más de la libertad religiosa en México. $\mathrm{Y}$ atendiendo a la dinámica constitucional, también será la manera como el Estado mexicano aplique directamente algunos de los derechos humanos expresamente estatuidos por tratados internacionales, cuyo alcance es, aparentemente, mayor que los del derecho interno, y con ello, finalmente, le de sentido a las reformas constitucionales de 2011. 


\section{BIBLIOGRAFÍA}

Alexy, R. (2007). Teoría de los derechos fundamentales. Madrid: CEPC.

Carbonell, M. (2004). Los derechos fundamentales en México. México DF: UNAM.

Celador Angón, O. (2009). Derecho a la educación, libertad de enseñanza y laicidad del Estado. Estado aconfesional y laicidad (pp. 47-109). Madrid: Consejo General del Poder Judicial.

Contreras Mazario, J. M. (2002). Laicidad del Estado y asistencia religiosa en centros docentes. Madrid: Dykynson.

Consejo de Derechos Humanos (2010). Informe A/HRC/16/53.

Cossío Díaz, J. R. (1989). Estado social y derechos de prestación. Madrid: Centro de Estudios Constitucionales.

- (2015). Bosquejos Constitucionales II. México: Porrúa.

Del Águila, R. (2010). La tolerancia. En A. Arteta et al. (eds.). Teoría política: poder, moral, democracia (pp. 362-383). Madrid: Alianza Editorial.

McConnell, M. W. (2013). Why Protect Religious Freedom? The Yale Law Journal, 123 (3), $770-810$.

Office for Democratic Institutions and Human Rights (2008). Principios orientadores de Toledo sobre la enseñanza acerca de las religiones y creencias en las escuelas públicas. Varsovia: OSCE.

Ollero, A. (2009). Un Estado Laico. La libertad religiosa en perspectiva constitucional. Pamplona: Aranzadi.

- (2010). Laicidad y laicismo. México DF: UNAM.

Porras Ramírez, J. M. (2013). Derecho de la libertad religiosa. Madrid: Tecnos.

Presidenza del Consiglio dei Ministri (2013). L'esercizio della libertà religiosa in Italia. Roma: Presidenza del Consiglio dei Ministri.

Santamaría, F. (2012). ¿Un mundo sin Dios? Madrid: RIALP.

Soberanes Fernández, J. L. (2000). Derechos de los creyentes. México DF: IIJ UNAM.

Soto Flores, A. (2013). El art. $3^{\circ}$ constitucional: Un debate por el control de las conciencias. Cuestiones Constitucionales, 28, 211-240.

Vázquez Alonso, V. J. (2012). Laicidad y Constitución. Madrid: CEPC.

Zagrebelsky, G. (2011). El derecho dúctil. Madrid: Trotta. 